\title{
Tribological investigation on oil blended with Additive using Response surface methodology
}

\author{
Tushar Gadekar ${ }^{1, *}$, Dinesh Kamble ${ }^{1}$ \\ ${ }^{1}$ Vishwakarma Institute of Information Technology Pune 411048, India
}

\section{Abstract.}

\begin{abstract}
Friction and wear in dynamic parts is the primary reason for energy loss in gearbox lubrication system and this can be optimized by utilizing modified lubricant. The tribological nature of gearbox system is critically affected by factors such as type of lubricant, loading \& speed etc. In latest years, multiple advanced oil and modern tribological techniques $\&$ instruments have been utilized to investigate behaviour of oil like pin on disc, Fourball tester etc. This paper presents comparative investigation of oil blended with additive for two different conditions using prediction model \& RSM. The design of experimentations has been conducted by using response surface methodology. The value of inputs parameters such as concentration, load \& sliding velocity ranges from 0.5 to $5 \%, 60$ to $100 \mathrm{~N}$ and 0.65 to $1.5 \mathrm{~m} / \mathrm{s}$, respectively are utilized to evaluate the outcomes of coefficient of friction and specific wear rate. At the end results from Prediction equations are compared with experimental literature based outcomes to signify the effect of parameters like blend $\%$, load $\&$ Sliding speed. The Coefficient of friction model showed $47.57 \%$ more closer outcomes as compared to the Specific wear rate model for specific variation of unknown parameters for pin on disc setup in oil.
\end{abstract}

\section{Introduction}

Lubricants are broadly used in the manufacture and engineering zones, along with consumed in automotive and several products to advance the softness of motion between two faces of material and therefore shrink the friction \& wear factors in between these studied faces. The prime function of oil is to drop friction, avoid wear of material, soak up heat, avoid rust as well as reduce pollution. Also, it's necessary that a lubricant would be capable to circulate easily adequate to take in and leave generated heat. The additives present in oil advance and reinforce the life of lubricants in various lubrication systems like engine, gearbox, bearing etc.

\subsection{Importance of Problem}

The low rotating speed of the main shaft with in a wind turbine needs the use of a turbine gearbox in order to increase the rpm of the secondary shaft until the true angular velocity values used for the generator are reached. The gearbox in wind turbine system has dominant maintenance as compared to other component . One of the key issue associated with wind turbine system is the optimal viscosity and anti-scuffing parameter reached at temp. beyond $80^{\circ} \mathrm{C}$ [1]. Friction and wear reduction is critical problem in such application due to its impact on the energy consumption and maintenance costs. High quality lubrication is required in such applications to overcome the problem. Current assessments proved that $33 \%$ of the fuel energy in car is lost due to friction in an engine, trans- mission, tires and brakes, and only $21.5 \%$ of the energy is used to move the car [2]. One of a chief losses happening in an IC engine is due to friction between its dynamic engine parts. This loss is considerable and approximately $15 \%$ of the total loss of energy and has a direct impact on the efficiency and durability of the machine.

\subsection{Current Status}

Recent researchers are concentrated on refining performance of lubricating oil by referring different additives. The influence of add-ons on lubricant performance has been investigated by using pin on disc type tribometer. On the other side there is less investigation on influence of Composite additives on tribological performance of oil in heavy load system like Wind turbine gearbox. Also some of researcher investigated impact of ionic liquid as add-ons on gearbox oil using tribometer but the drop in friction parameter not observed significantly in study.

\section{Literature review}

The literature study on experimental examination of lubrication nature of various lubricants blended with add-ons \& influence of it on COF, wear, viscosity are reviewed and reported under.

*orresponding author: tdgadekar13.scoe@gmail.com 


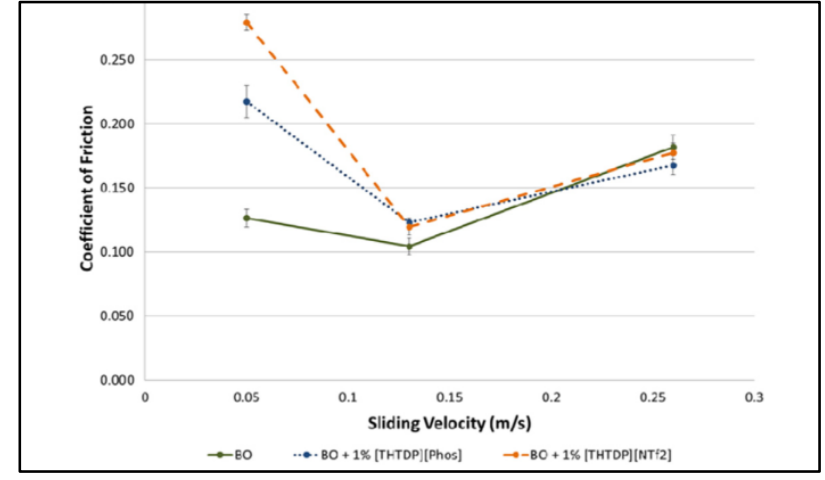

Fig. 1. Coefficient of friction model behavior for oil blended with Ionic Liquid [3]

R. Monge et al. [1] have investigated friction \& wear performance of Ionic liquids as add-ons in gearbox oils. In an investigation two distinct ionic liquids 5 wt. \% concentration are utilized for examination in wind turbine lubrication system. The Investigation result has showed that used additive have a less friction altering feature but a significant wear reducing performance.

The Lubrication skill of ionic liquids as add-ons in a biooil for gearbox lubrication system has been investigated for various sliding velocity [3]. An occurence of the ionic liquid add-on effectively decreases a volume loss in track, particularly under larger speed \& reduces less Coefficient of friction as shown in Figure 1. Marques et al. [4] have studied efficiency of a gearbox lubricated with wind turbine gear oils. The examination showed that amongst the investigated gear lubricants the Glycol grounded oil has showed healthier than any further of a selected gear lubricants. Greco et al. [5] have reported wear \& Friction performance of boron based surface treatment and Nano-particle lubricant additives for gearbox of wind turbine. The authors have suggested a combined way to include electrochemical boriding in synchronisation with the use of Nano additives.

A. Greco et al. [6] have reported material friction \&wear parameter in turbine Structures. This article reports contact failures of bearings from wind turbine gearboxes. The investigation showed that microstructural alteration has been seen closer to the surface. The experimental study on oil blended with single additive by using various types of tribometer is presented for cases like Gearbox, Engine, Bearing etc [2, 3, 8-16].

M. Husnawan et al. [17] have developed friction force Prediction Equation for oil base stock inclosing palm olein $\&$ anti-wear additive. Tribological experiment was carried on four ball tester \& model force developed by using wear load, speed \& operating time. The Response surface methodology (RSM) has been utilized statistical model development.
M. H. Sakinah et al. [18] have presented the use of DOE method in the investigation of the Tribological outcome of Palm Cooking lubricant mixed in Engine oil. The DOE has been assembled by using Response surface methodology to reduce experimental conditions and to develop a mathematical model between parameters such as rotational speeds, volume concentration, and applied loads. Analysis of variance (ANOVA) test has been carried out to check the adequacy of the empirical models developed.

Yashvir Singh et al. [23] have optimized tribological characteristics of seed oil using response surface methodology. The tribological investigation has been conducted by using pin on disc instrument also statistical modelling of particular wear rate \& COF parameters has been done by using experimental results.

\section{Experimental Setup}

The experimental test Setup \& Parameters for tribological investigation of oil blended with additive are reported under.

\subsection{Parameter of investigation}

After a literature survey implementation it is revealed that several fundamental factors have been utilized in a Lubrication performance measurement. The performance measurement mainly includes investigation of friction coefficient, viscosity, wear etc. A detail summary of tribological performance measurement is shown in fig 2 .

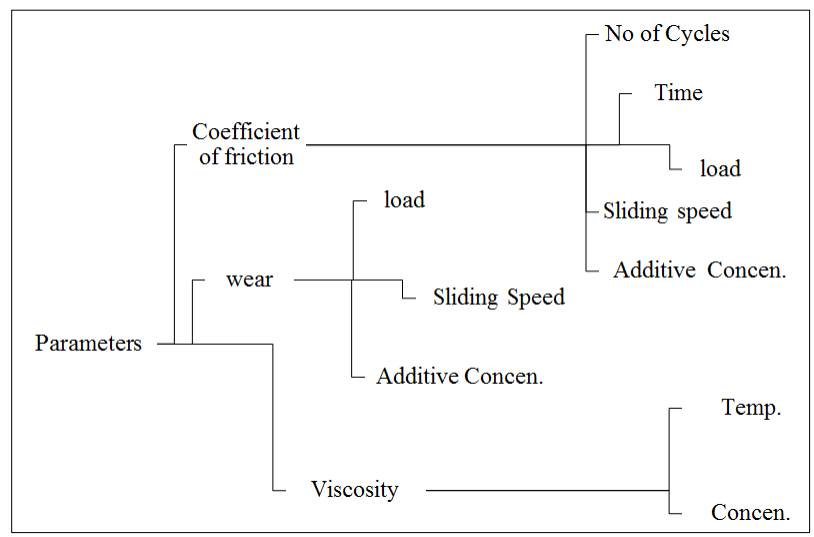

Fig. 2. Parameters in tribological study of oil

\subsection{Pin on disc instrument}

The Pin-on-disc type configuration is used to investigate coefficient of friction \& wear in sliding contact as shown Figure 3. 


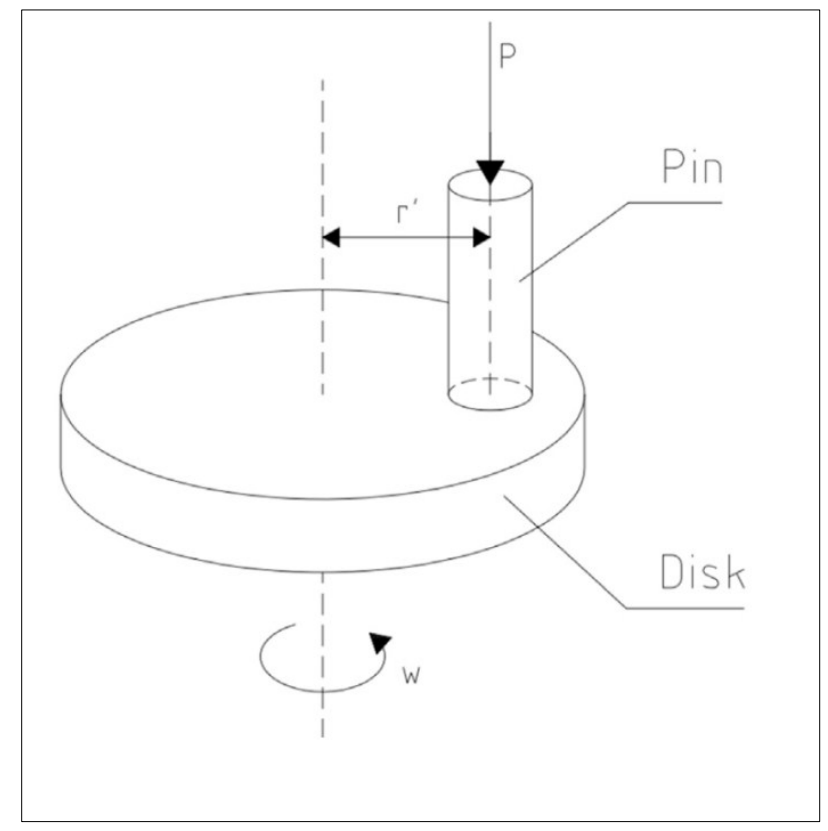

Fig. 3. Pin on disc setup

The configuration includes cylinder-shaped pin counter to a rotating circular disc by a load ' $L$ '. For a pin-ondisc Arrangement two specimens are required namely disc \& pin of standard dimensions . The standards \& disc dimension for experimentation on pin on disc instrument is mentioned in Table 1.

Table 1. Pin on disc test standard

\begin{tabular}{|c|c|c|c|}
\hline $\begin{array}{c}\text { Pin diameter } \\
\text { range } \\
\text { in } \mathbf{m m}\end{array}$ & $\begin{array}{c}\text { Disc } \\
\text { specimen } \\
\text { diameters } \\
\text { in } \mathbf{m m}\end{array}$ & $\begin{array}{c}\text { Disc } \\
\text { specimen } \\
\text { Thickness } \\
\text { in } \mathbf{m m}\end{array}$ & Standard \\
\hline 2 to 10 & 30 to 100 & 2 to 10 & G99 \\
\hline
\end{tabular}

\subsection{Coefficient of friction \& Wear rate model for Pin on Disc test}

The quadratic models for specific wear rate and Coefficient of friction for Pin on disc setup is given below,

\section{$\mathrm{COF}=$}

$\left.0.039497-\left(4.76850 \times 10^{-4}\right) \times \mathrm{B}\right)+\left(4.475 \times 10^{-5} \times \mathrm{L}\right)-($ $\left.3.93760 \times 10^{-3} \times \mathrm{S}\right)-\left(5.0 \times 10^{-8} \mathrm{~B} \times \mathrm{L}\right)+\left(1.2 \times 10^{-5}\right.$ )$\left.\times \mathrm{B} \times \mathrm{S})+\left(2.78750 \times 10^{-5} \times \mathrm{B}^{2}\right)-\left(5.00 \times 10^{-9}\right) \times \mathrm{L}^{2}\right)-$ $\left.\left(2.400 \times 10^{-5}\right) \times \mathrm{S}^{2}\right)$

Wear $=$

$\left.\left.1.37377 \times 10^{-5}\right)-\left(4.6299 \times 10^{-7}\right) \times \mathrm{B}\right)+\left(6.8257 \times 10^{-8} \times \mathrm{L}\right)-$ $\left(3.3852 \times 10^{-6} \times \mathrm{S}\right)-\left(2.45 \times 10^{-11} \times \mathrm{B} \times \mathrm{L}\right)+\left(1.18 \times 10^{-}\right.$

$$
\begin{aligned}
& \left.{ }^{8} \times \mathrm{B} \times \mathrm{S}\right)-\left(8.20560 \times 10^{-10} \times \mathrm{L} \times \mathrm{S}\right)+\left(2.9357 \times 10^{-8} \times \mathrm{B}^{2}\right)- \\
& \left.\left(1.05993 \times 10^{-10} \quad \times \mathrm{L}^{2}\right) \quad-\quad\left(1.34229 \times 10^{-7}\right) \times \quad \mathrm{S}^{2}\right) \\
& \text { (2) [23] }
\end{aligned}
$$

Where, B is the blend percentage, L is the load in N, S is the sliding velocity in $\mathrm{m} / \mathrm{s}$

\section{Design of Experiment}

The Design of experiment for gearbox oil blended with additives is mentioned under. The experimental run suggested by Central composite design of response surface approach has been presented.

\subsection{Response surface methodology}

Response surface methodology is the method to choose numerous relations between progression parameters and tribological parameters and discover the influence of these progression parameters on the combined responses.Fig.4.

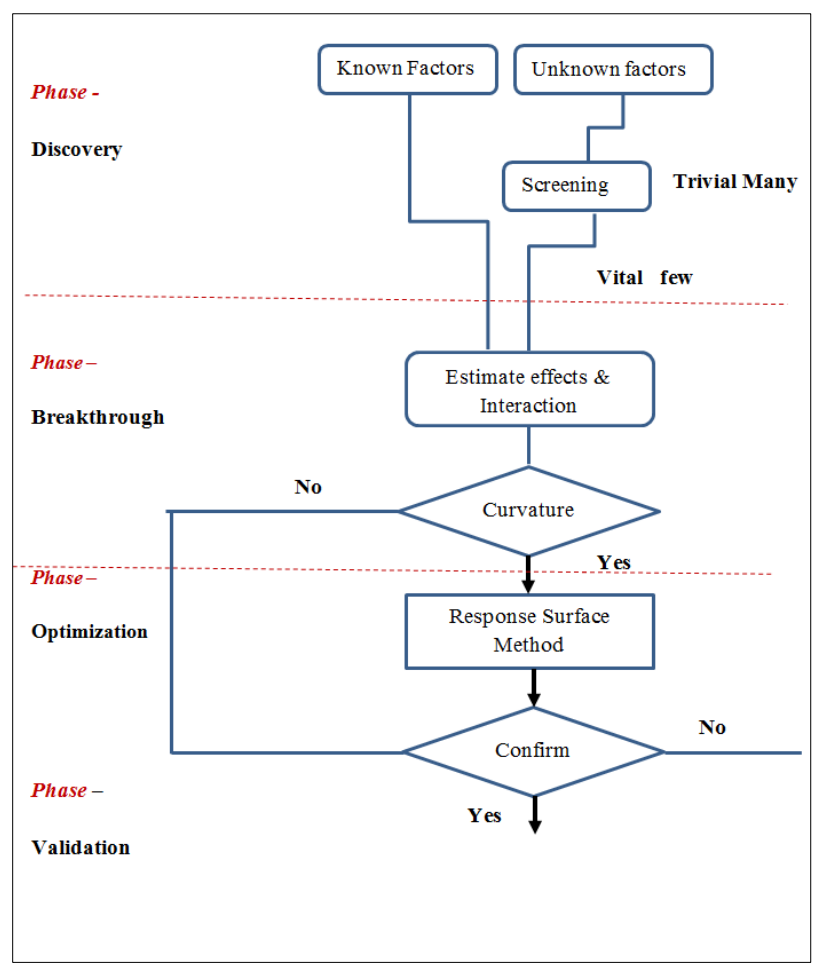

Fig. 4. Steps in RSM

RSM is deal with the usage of factorial design .In RSM the crucial effect of a factor is well-defined as the deviation in response initiated by a variation in a level of the factor considered like Concentration or Speed or Load etc., while the other parameters are retained constant.

\subsection{DOE by Response surface methodology}


The experimental trial suggested by CCD Approach of response surface approach has been developed on Design expert ${ }^{\circledR}$ Software. Table 2 shows the appropriate levels of variables referred to design the factors for a tribological experiment on pin on disc Tribometer.

Table 2. values of independent parameters

\begin{tabular}{|c|c|c|}
\hline Parameters & $\mathbf{- 1}$ & $\mathbf{1}$ \\
\hline Load in (N) & 60 & 100 \\
\hline $\begin{array}{c}\text { Concentration } \\
\text { in wt. \% }\end{array}$ & 0.5 & 5 \\
\hline $\begin{array}{c}\text { Sliding } \\
\text { velocity in } \mathrm{m} / \mathrm{s}\end{array}$ & 0.65 & 1.5 \\
\hline
\end{tabular}

In DOE three parameters considered as a known parameter namely Load, Concentration ,sliding velocity, which has 2 levels each hence for CCD with 3 center points 17 runs obtained from Design expert ${ }^{\circledR}$.Table 3 shows the Design of experiment using by Response surface methodology .

Table 3. Design of experiment using CCD

\begin{tabular}{|c|c|c|c|}
\hline Run & $\begin{array}{c}\text { Load } \\
\text { in N }\end{array}$ & Concentration & $\begin{array}{c}\text { Sliding } \\
\text { Velocity }\end{array}$ \\
\hline 1 & 60 & 5.00 & 1.50 \\
\hline 2 & 114 & 2.75 & 1.08 \\
\hline 3 & 80 & 2.75 & 0.36 \\
\hline 4 & 80 & 6.53 & 1.08 \\
\hline 5 & 60 & 5.00 & 0.65 \\
\hline 6 & 100 & 5.00 & 1.50 \\
\hline 7 & 100 & 5.00 & 0.65 \\
\hline 8 & 80 & 2.75 & 1.08 \\
\hline 9 & 46 & 2.75 & 1.08 \\
\hline 10 & 60 & 0.50 & 1.50 \\
\hline 11 & 100 & 0.50 & 0.65 \\
\hline 12 & 80 & 2.75 & 1.79 \\
\hline 13 & 80 & 2.75 & 1.08 \\
\hline 14 & 80 & 2.75 & 1.08 \\
\hline 15 & 60 & 0.50 & 0.65 \\
\hline 16 & 100 & 0.50 & 1.50 \\
\hline 17 & 80 & -1.03 & 1.08 \\
\hline & & & \\
\hline
\end{tabular}

\section{DOE vs. Experimental literature based results}

The design of experiment \& experiment literature based results of tribological parameter for Coefficient of friction \& specific wear rate model is presented under.
The Coefficient of friction model results for various 17 trials of independent parameters are presented in Figure 5. In literature based inputs the maximum value of Coefficient of friction model is $0.0406 \&$ minimum value is 0.0248 .

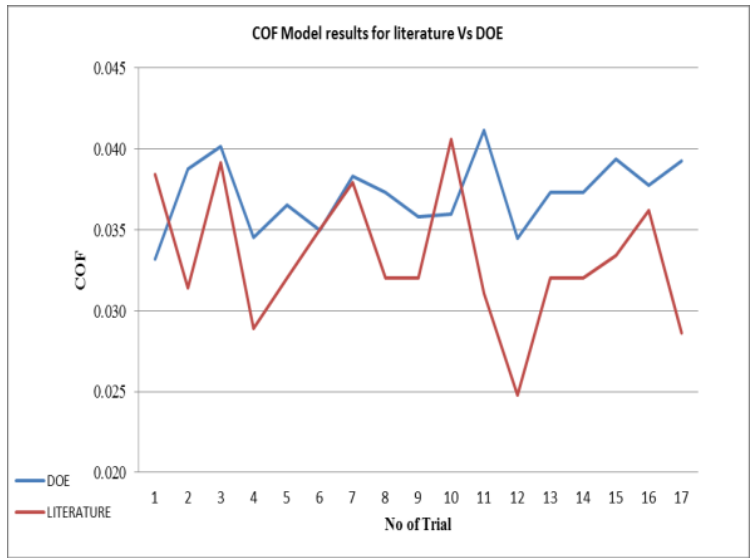

Fig. 5. Coefficient of friction values for DOE \& Literature

In CCD based inputs the maximum value of COF model is $0.0411 \&$ minimum value is 0.033 shown in Fig.5.In COF based results analysis most of the values of DOE varies in parallel pattern as that of Literature values.

\subsection{Wear}

The wear outcomes for both inputs shown in Figure 6. In literature based inputs the maximum value of specific wear rate in $\left(\mathrm{mm}^{3} / \mathrm{Nm}\right)$ model is $1.69 \times 10^{-5} \&$ minimum value is $9.71 \times 10^{-8}$.

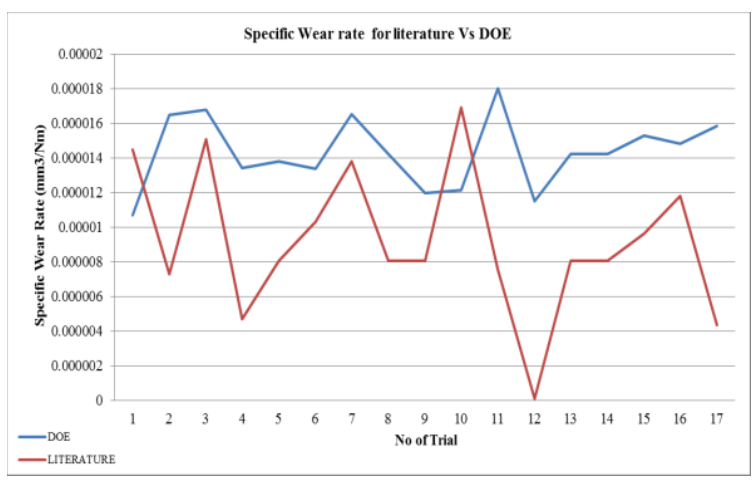

Fig. 6. Wear values for DOE \& Literature inputs

In DOE based inputs the maximum value of specific wear rate in $\left(\mathrm{mm}^{3} / \mathrm{Nm}\right)$ model is $1.80 \times 10^{-5} \&$ minimum value is $1.072 \times 10^{-5}$. In Specific wear rate based results analysis most of the values of DOE varies in in extreme pattern as that of Literature outcomes.

\subsection{Coefficient of friction}




\section{Conclusion}

Wear and friction drop is critical issue in gearbox systems and it can be resolved by using high performance modified Lubricant. The Prediction model results for literature \& CCD based inputs are compared \& investigated by referring 17 trials for various conditions for Pin on disc setup. On the origin of present comparative investigation particular important findings are given as:

1. Response surface methodology (CCD) \& literature based values are compared for pin on disc setup and the comparative examination revealed that $23.5 \%$ closer values to experimental reference values in COF model, the specific wear rate model showed $11.7 \%$ closer values to experimental values.

2. In COF model the maximum value of Coefficient of friction is 0.0411 \& 0.0406 for CCD \& Experimental literature based inputs respectively. Also the minimum value of $\mathrm{COF}$ is 0.0248 found in experiment literature outcomes.

3. In specific wear rate model the extreme variation in curves are observed for 17 trials of tribological examination.

4. The extreme specific wear rate value for CCD based inputs is $1.80 \times 10^{-5} \mathrm{~mm}^{3} / \mathrm{Nm} \&$ the minimum value is observed for trial 12 .

5. The Coefficient of friction model showed $47.57 \%$ more closer outcomes than Specific wear rate model for specific variation of unknown parameter like load, blend $\%$ \& sliding velocity.

\section{References}

1. R. Monge, R.González, A.Hernández Battez, A.Fernández-González, J.L.Viesca, A.García, Wear, 50-63(2015).

2. Z. Y. Xu, K. H. Hu, Y. K. Cai, F. Huang and C. L. Han, 1-7 ( 2014);

3. Edward Cigno, Christina Magagnoli, Michael S. Pierce, P. Iglesias, Wear, 756-765 (2017).

4. Pedro M.T.Marques, Carlos M.C.G.Fernandes, Ramiro C.Martins, Jorge H.O.Seabra, Tribology International, 71,7-16 (2014).

5. A. Greco, K. Mistry, V. Sista, wear, 271,1754-1760 (2011).

6. A. Greco, S.Sheng, J.Keller, A.Erdemir, wear, 302; 1583-1591(2013).

7. Naveenkumar Rajendhran, Siva Palanisamy, Arunkumar Prabhakaran Shyma, Rajendran
Venkatachalam, Tribology International, 156-168 (2018).

8. Carlos M.C.G.Fernandes, Pedro M.T.Marques, RamiroC.Martins, Jorge H.O.Seabra,Tribology International, (2014).

9. Carlos M.C.G.Fernandes, Pedro M.T.Marques, Ramiro C.Martins, Jorge H.O.Seabra, 88, 309316(2015).

10. Meena Laad,Vijay Kumar S. Jatti, Journal of King Saud University - Engineering Sciences, (2016).

11. W. Gregory Sawyer, John C. Ziegert, Tony L. Schmitz \& Timothy Barton, Iranian Polymer Journal, 284-290(2006).

12. Lin Zhang, Dapeng Feng, Bin Xu,Tribol Lett,95-101 (2009) .

13. M.S. Charoo, M.F. Wani, Tribology Industry, 156162 (2016) .

14. Fatima Leonor Guzman Borda, Sylvio Jos_e Ribeiro de Oliveira, Leticia Maria Seabra Monteiro Lazaro, Albino Jos_e Kalab Leir, Tribology International, 52-58(2018).

15. Kai Gao, Qiuying Chang, Bin Wang, Ningning Zhou, Tao Qing, ( 2018).

16. A. Vadiraj, G. Manivasagam, K. Kamani, V.S. Sreenivasan, Tribology in Industry, (2012):1; 3-10

17. M. Husnawan, M.G. Saifullah, H.H. Masjuki, Tribology International, 74-81 (2007).

18. M. H. Sakinah, A. K. Amirruddin, K. Kadirgama, D. Ramasamy, M. M. Rahman, \& M.M. Noor, Advances in Tribology, 1-11(2016).

19. Sheida Shahnazar, Samira Bagheri \& Sharifah Bee Abd Hamid, International journal of hydrogen energy, 1-18(2015).

20. Mohammad Hemmat Esfea, Ali Akbar Abbasian Aranib \& Saeed Esfandehb, Applied Thermal Engineering, 493-506(2018).

21. Ting Luo,Xiaowei Wein, Haiyan Zhao,Guangyong Cai, Xiaoyu Zheng, ceramics international, 1010310109(2014).

22. Zhenyu J. Zhang, Dorin Simionesie and Carl Schaschke, lubricants, 44 -65(2014).

23. Yashvir Singh, Paramvir Singh, Abhishek Sharma, Praveen Choudhary, Amneesh Singla, Nishant Kumar Singh, Egyptian Journal of Petroleum, 11451155(2018). 